\title{
Effect of Composition of Immersion Nozzle on Occurrence of Blister in Steel Sheet
}

\author{
Katsuhiro SASAI and Yoshimasa MIZUKAMI \\ Nagoya R \& D Laboratories, Nippon Steel Corporation, Tokai-machi, Tokai, Aichi-ken, 476 Japan.
}

(Received on May 22, 1995; accepted in final form on July 24, 1995)

\begin{abstract}
The effect of the inner porous refractories-molten steel reaction on the incidence of blisters and the mechanism whereby the incidence of blisters is prevented by using an immersion nozzle with a silicaless inner porous refractories that does not react with the molten steel were studied. The following results were obtained:
\end{abstract}

(1) Blisters are caused by $0.5 \mathrm{~mm}$ and larger argon gas bubbles, and particularly $1.0 \mathrm{~mm}$ and larger argon gas bubbles have a strong bearing on the incidence of blisters in the sheet product.

(2) The mechanism whereby the incidence of blisters depends on the number of sequence cast heats can be explained by the increase in argon gas bubble diameter caused by the inner porous refractories-molten steel reaction in the later heats in the sequence cast.

(3) Fine argon gas bubbles can be stably introduced into the molten steel by using an immersion nozzle with a silicaless inner porous refractories that does not react with the molten steel. This stable injection of fine argon gas bubbies helps prevent the occurrence of blisters in the sheet product.

KEY WORDS: argon gas bubble; blister; immersion nozzle; bubble diameter; silica; alumina graphite; refractories.

\section{Introduction}

Argon gas is injected from the porous refractories in the inner wall (inner porous refractories) of the immersion nozzle to prevent nozzle clogging. Some of the argon gas bubbles injected into the molten steel are entrapped at the solidification front in the slab. Large argon gas bubbles are not welded shut after hot and cold rolling and appear as blisters on the sheet steel surface. ${ }^{1)}$ For this reason, stable injection of fine argon gas bubbles is extremely important for assuring desired cast slab quality. The authors conducted a series of studies on the mechanism of reaction between refractories and molten steel. ${ }^{2,3)}$ According to the results of the study, they believe that, by preventing inner porous refractoriesmolten steel reaction, fine argon gas bubbles can be stably and uniformly injected into the molten steel. From this consideration, they worked on the research and development of an immersion nozzle having a silicaless inner porous refractories that does not react with the molten steel.

The present study clarified the effect of the inner porous refractories-molten steel reaction on the occurrence of blisters and investigated the mechanism whereby the occurrence of blisters can be prevented by using an immersion nozzle having a silicaless inner porous refractories that does not react with the molten steel.

\section{Experimentals}

\subsection{Casting Experiment}

An immersion nozzle made of alumina graphite having a silica-containing inner porous refractories (C: $22 \%$, $\mathrm{SiO}_{2}: 25 \%, \mathrm{Al}_{2} \mathrm{O}_{3}: 47 \%$, SiC: $6 \%$ ) and an immersion nozzle made of alumina graphite having a silicaless inner porous refractories $\left(\mathrm{C}: 20 \%, \mathrm{SiO}_{2}: \operatorname{tr}, \mathrm{Al}_{2} \mathrm{O}_{3}: 73 \%, \mathrm{SiC}\right.$ : $7 \%$ ) were used in the casting experiment. The gas flow characteristics of the immersion nozzle were evaluated by measuring the total cold gas flow rate and the cold gas flow rate through the inner porous refractories as described in the previous report. ${ }^{4)}$

The twin-strand No. 1 continuous casters at the Nagoya Works were simultaneously equipped with these two types of immersion nozzles and used to mainly cast titanium-treated ultralow-carbon steel or interstitial-free (IF) steel. The total hot gas flow rate ${ }^{4)}$ was 8.30 $\mathrm{Ncm}^{3} \cdot \mathrm{cm}^{-2} \cdot \mathrm{min}^{-1}$, and the hot argon gas inlet pressure was continuously measured throughout the casting operation. Some slabs were examined in the cross section by $\mathrm{X}$-ray radiography to find out the number of argon gas bubbles entrapped over $300 \mathrm{~mm}$ from either edge thereof where blisters occur and the number of blisters formed after the hot rolling step was also counted.

\subsection{Examination of Inner Porous Refractories of Immersion Nozzles}

Specimens, measuring $15 \mathrm{~mm}$ by $15 \mathrm{~mm}$ by $10 \mathrm{~mm}$ to $12 \mathrm{~mm}$ (inner porous refractories thickness), were machined from the inner porous refractories of unused 
and used immersion nozzles. The inner porous refractories are cylinders, measuring $277 \mathrm{~mm}$ in height, $90 \mathrm{~mm}$ in inside diameter, and 110 to $114 \mathrm{~mm}$ in outside diameter. The appearance and microstructure of the cross section of the inner porous refractories specimens were observed. To quantitatively determine the alteration of the inner porous refractories structure, the cross-sectional thickness of the reacted zone and porosity of the inner porous refractories specimen were also measured.

\subsection{Argon Gas Bubbling Experiment}

A silicone tube $(6 \mathrm{~mm}$ in inside diameter and $11 \mathrm{~mm}$ in outside diameter) was attached to the side opposite to the molten steel contact side of an inner porous refractories specimen and this specimen was embedded with resin in a polyvinyl chloride (PVC) pipe $(20 \mathrm{~mm}$ in inside diameter and $26 \mathrm{~mm}$ in outside diameter) to make an argon gas bubbling plug. The bubble formation surface of the specimen was sealed with an adhesive to keep the bubble formation range constant at $10 \mathrm{~mm}$ by $10 \mathrm{~mm}$. The argon gas bubbling plug thus fabricated was set in water and used in the argon gas bubbling experiment as illustrated in Fig. 1. The argon gas was injected at room temperature, a pressure of $0.196 \mathrm{MPa}$, and a flow rate of $20 \mathrm{~cm}^{3} \cdot \mathrm{cm}^{-2} \cdot \mathrm{min}^{-1}$. The hot argon gas inlet pressure and hot gas flow rate through the inner porous refractories of the immersion nozzle on

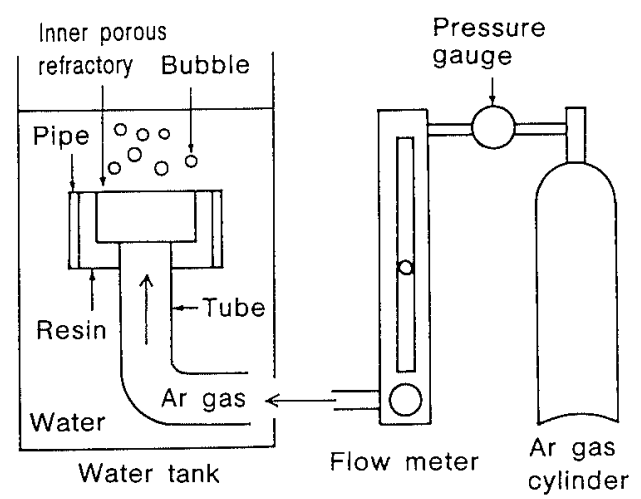

Fig. 1. Experimental apparatus for argon gas bubbling.

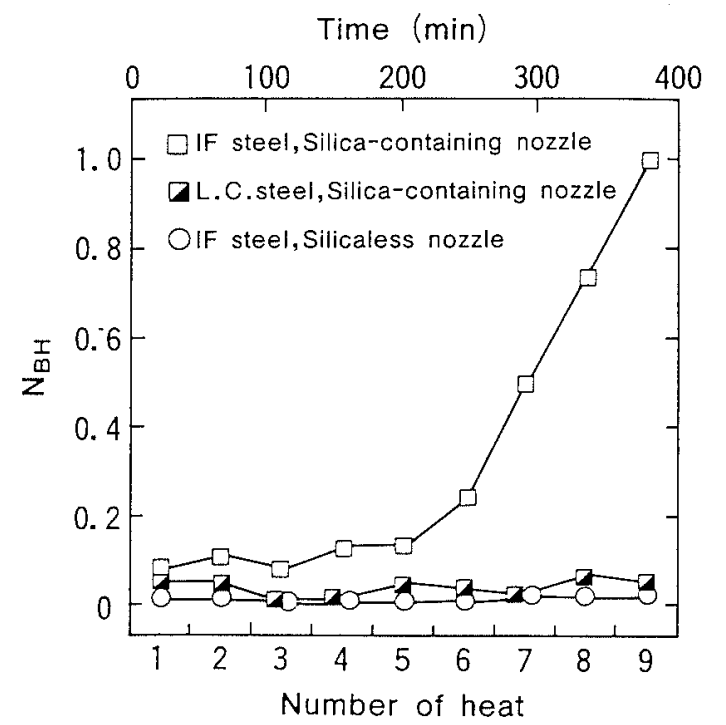

Fig. 2. Relationship between index for number of blisters $N_{\mathrm{BH}}$ and number of heats in sequence cast. the continuous caster were 0.05 to $0.20 \mathrm{MPa}$ and 24.5 $\mathrm{cm}^{3} \cdot \mathrm{cm}^{-2} \cdot \mathrm{min}^{-1}$ (when converted at the hot argon gas temperature of $\left.1073 \mathrm{~K}^{4)}\right)$, respectively. The argon gas bubbles injected into the water were photographed at a high speed of one frame per $1 / 1000 \mathrm{~s}$, and the average argon gas bubble diameter was measured by an image analyzer.

\section{Experimental Results}

Figure 2 shows the relationship between the index $N_{\mathrm{BH}}$ for the number of blisters in the sheet product and the number of heats in a sequence cast. Maximum value of the number of blisters in a coil of sheet product was defined as 1.0 in the index $N_{\mathrm{BH}}$ for the number of blisters. When low-carbon aluminum-killed steel and IF steel were cast by using the immersion nozzle with the silicacontaining inner porous refractories, the blisters occurred more frequently in the IF steel than the low-carbon aluminum-killed steel and exhibited steel grade dependence. The incidence of blisters was high in the later heats in the sequence cast, especially after heat 6 (225 min), and exhibited sequence cast heat number dependence as well. The occurrence of blisters drastically declined when the immersion nozzle with the silicaless inner porous refractories, was used.

Figure 3 shows the change in the argon gas flow index of the immersion nozzles with time. The argon gas flow index is the total hot gas flow rate $Q_{\mathrm{H}}$ divided by the hot argon gas inlet pressure $p_{\mathrm{H}}$ and made dimensionless by the $Q_{\mathrm{H} 1} / p_{\mathrm{H} 1}$ ratio of the first heat. With an increase in the casting time, the argon gas flow index gradually increases for the immersion nozzle with the silica-containing inner porous refractories while remaining almost constant throughout the sequence cast for the immersion nozzle with the silicaless inner porous refractories.

The cross sections of specimens taken from the $1 / 2$ height positions of the inner porous refractories of the immersion nozzles after nine heats are shown in Fig. 4. A gray reacted zone formed on the molten steel contact surface of the silica-containing inner porous refractories used to cast the IF steel is thicker than that formed on

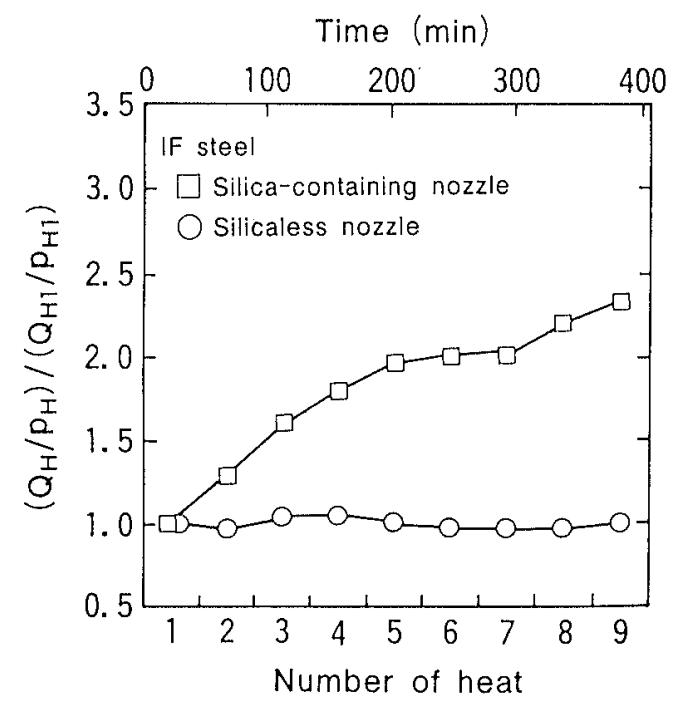

Fig. 3. Relationship between argon gas flow index $\left(Q_{\mathrm{H}} / p_{\mathrm{H}}\right) /$ $\left(Q_{11} / p_{H 1}\right)$ and number of heats in sequence cast. 
such a surface of the silicaless inner porous refractories used to cast the IF steel. A reacted zone of the silicacontaining inner porous refractories used to cast the IF steel was thicker than that of the silica-containing inner porous refractories used to cast low-carbon aluminumkilled steel.

Figure 5 shows the argon gas bubbles injected from the inner porous refractories of Fig. 4 by the method illustrated in Fig. 1. The argon gas bubbles injected from the used silica-containing inner porous refractories are of larger diameter than those injected from the unused silica-containing inner porous refractories. The diameter of the argon gas bubbles injected from the silicaless inner porous refractories is practically the same before and after casting or is not increased after casting. The diameter increase of the argon gas bubbles was more pronounced for the silica-containing inner porous refractories used to cast the IF steel than those used to cast the low-carbon aluminum-killed steel.

\section{Discussions}

4.1. Mechanism for Alteration of Inner Porous Refractories of Immersion Nozzles

The microstructures of the silica-containing inner porous refractories and silicaless inner porous refractories, both used to cast the IF steel, are shown in Fig. 6. There is little change in the microstructure of the silicaless inner porous refractories after casting, whereas the silica and carbon contents of the silica-containing inner porous refractories decline and many pores are formed therein, as already reported. ${ }^{2)}$

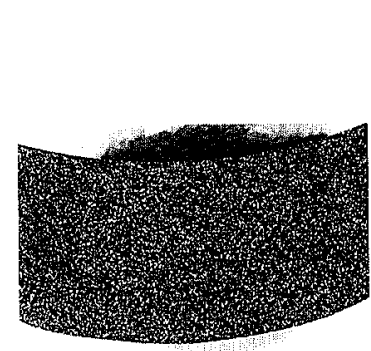

(a)

(b)
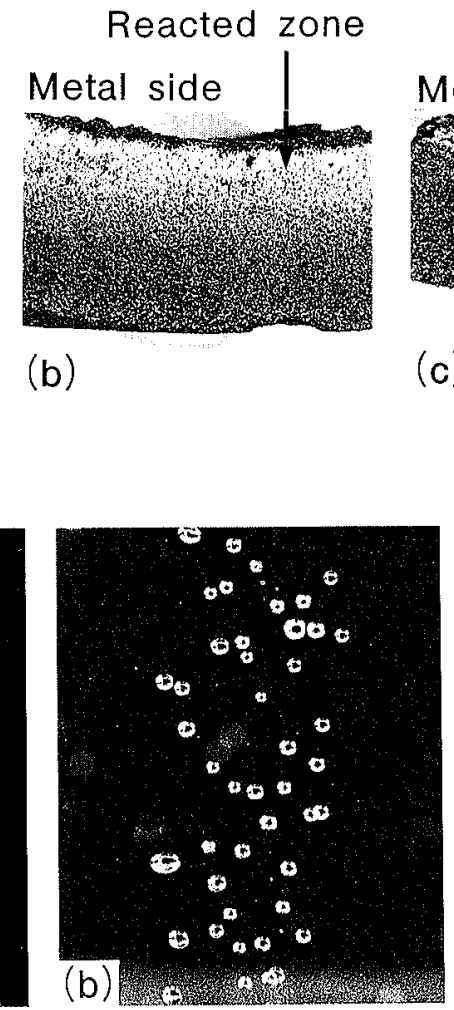

(a)

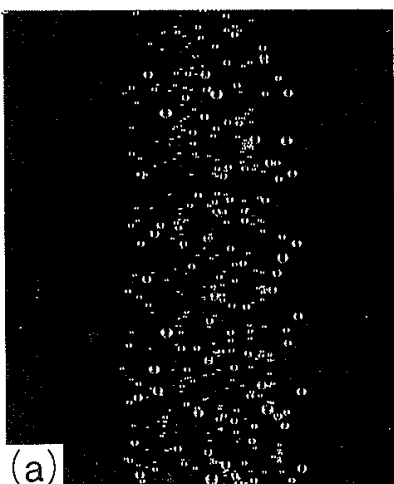

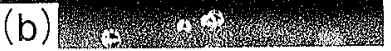
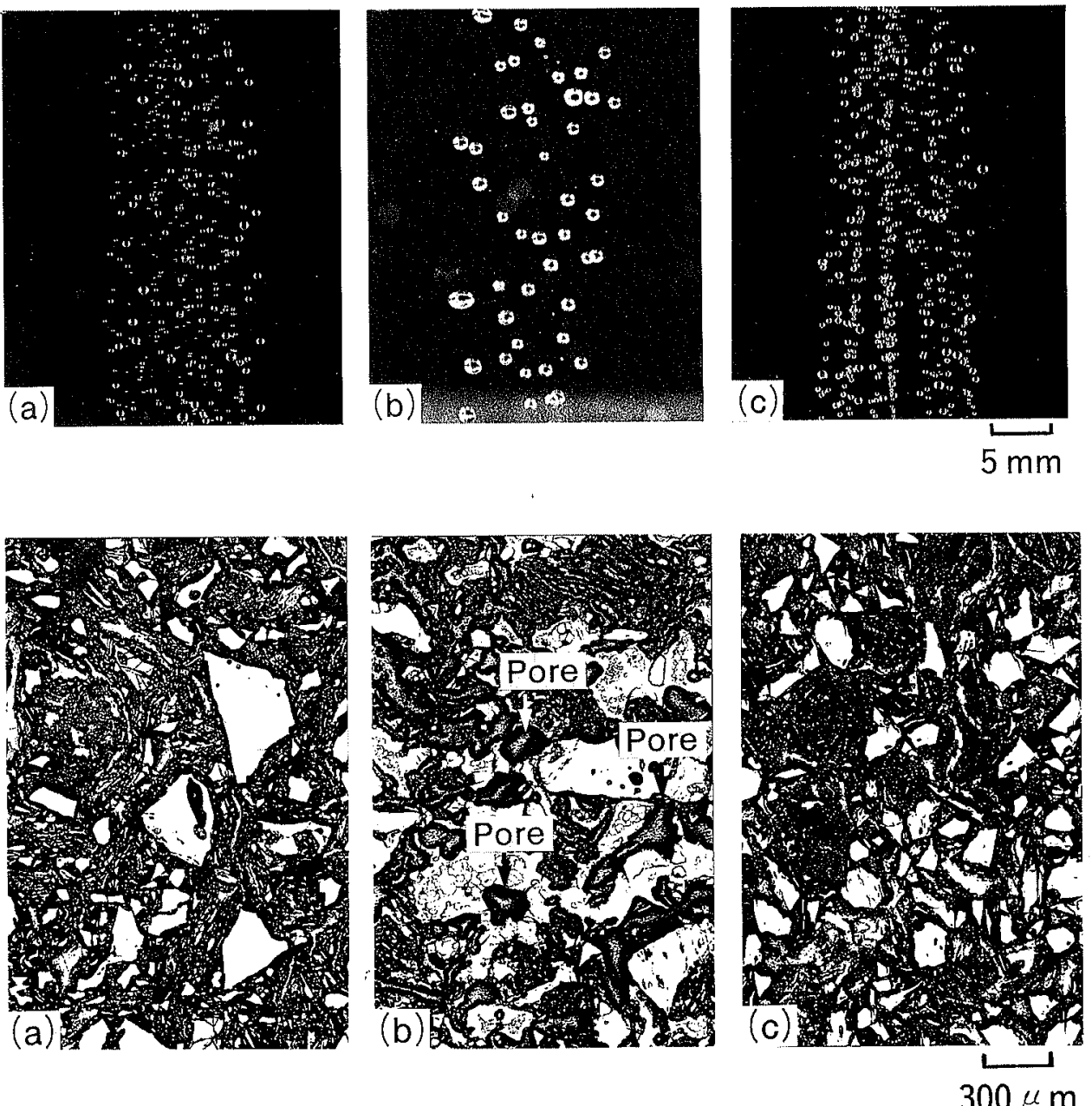

Fig. 4.

Cross-sectional photographs of inner porous refractories.

(a) Unused silica-containing inner porous refractories

(b) Silica-containing inner porous refractories after 9 heats of IF steel

(c) Silicaless inner porous refractories after 9 heats of IF steel
Fig. 5.

Photographs of argon gas bubbles injected from inner porous refractories.

(a) Unused silica-containing inner porous refractories

(b) Silica-containing inner porous refractories after 9 heats of IF steel

(c) Silicaless inner porous refractories after 9 heats of IF steel
Fig. 6.

Cross-sectional microstructures of inner porous refractories after casting.

(a) Unused silica-containing inner porous refractories

(b) Silica-containing inner porous refractories after 9 heats of IF steel

(c) Silicaless inner porous refractories after 9 heats of IF steel 
The authors studied the mechanism of reaction between silica-containing alumina graphite refractories and low-carbon molten steel from the standpoints of equilibrium and kinetics. ${ }^{2,3)}$ They found that silica in the alumina graphite refractories is reduced by carbon to form $\mathrm{SiO}$ and $\mathrm{CO}$ gases, that the $\mathrm{SiO}$ and $\mathrm{CO}$ gases react with the aluminum and titanium in the molten steel at the alumina graphite refractories-molten steel interface, that the rate of the alumina graphite refractories-molten steel reaction is strongly influenced by the gas diffusion through the oxide film formed at the alumina graphite refractories-molten steel interface, and that steel grade dependence appears according to the gas permeation of the oxide film. These findings suggest that the abovementioned reaction causes the silica and carbon to be simultaneously lost from the silica-containing inner porous refractories and a reacted zone to be formed and that the steel grade dependence of the reacted zone thickness is attributable to the difference between the gas permeation of the oxide film in the low-carbon aluminum-killed steel and that of the IF steel. The silicaless inner porous refractories has some of the graphite dissolved in the molten steel and a thin reacted zone formed on the surface. Since there is no reduction of silica by carbon, the reacted zone is not considered to expand inward for the silicaless inner porous refractories.

\subsection{Effect of Inner Porous Refractories Alteration on Bubble Diameter}

The relationship between the thickness of the reacted zone, $L_{\mathrm{R}}$, and the diameter of the argon gas bubbles in water, $D_{\mathrm{w}}$, is shown for immersion nozzle inner porous refractories after nine heats in Fig. 7. The argon gas diameter increases with an increase in the reacted zone thickness for the silica-containing inner porous refractories, but does not increase with an increase in the reacted zone thickness for the silicaless inner porous refractories. This difference may be explained as follows. Since the particle size of silica used in the silica-containing

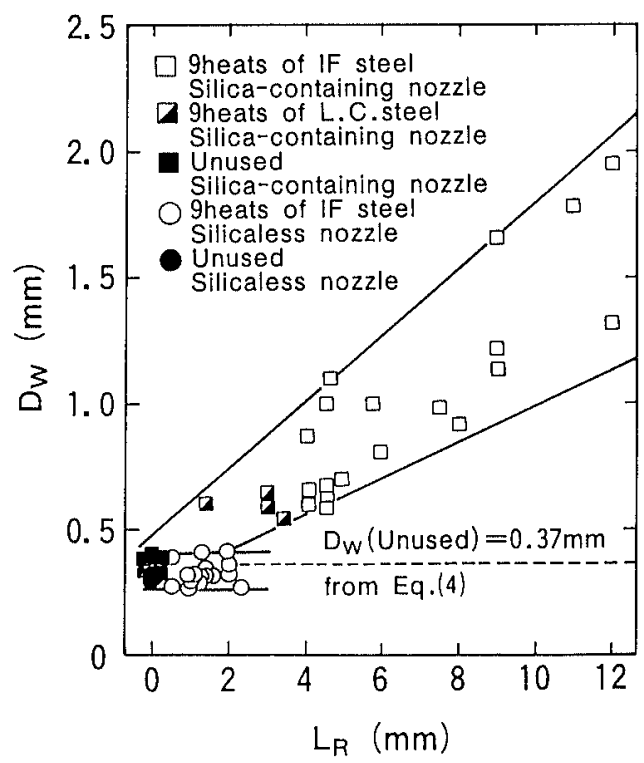

Fig. 7. Relationship between thickness of reacted zone $L_{\mathrm{R}}$ and diameter of argon gas bubbles in water $D_{\mathrm{w}}$. inner porous refractories is relatively large or about $200 \mu \mathrm{m}$ on average, the pores in the silica-containing inner porous refractories are increased in diameter by the loss of silica based on the inner porous refractoriesmolten steel reaction mentioned above. The silicaless inner porous refractories has surface flaky graphite solely lost due to its dissolution in the molten steel and changes little in pore diameter. The change with time in the gas flow index shown for the immersion nozzle with the silica-containing inner porous refractories and the immersion nozzle with the silicaless inner porous refractories in Fig. 3 can be similarly explained.

\subsection{Effect of Inner Porous Refractories Position on Bubble Diameter}

The silica-containing inner porous refractories in Fig. 7 are approximately the same in reaction time with the molten steel (after nine heats), but its reacted zone thickness and bubble diameter data are distributed over wide ranges. When the data are limited to those for the IF steel to eliminate the effect of steel grade dependence, the reacted zone thickness and the bubble diameter range from 4 to $12 \mathrm{~mm}$ and from 0.6 to $2.0 \mathrm{~mm}$, respectively. To identify the cause of these differences, the relationship between the porosity increase $\Delta \varepsilon$ as an index of inner porous refractories alteration after casting and the inner porous refractories position (distance $H_{1}$ from the top of the inner porous refractories) is arranged as shown in Fig. 8. Since the porosity of the same nozzle could not be measured before and after casting, the porosity increase was determined by reference to the porosity of an unused nozzle having the same total cold gas flow rate. The porosity of the silicaless inner porous refractories hardly increases after casting and does not vary with the position in the silicaless inner porous refractories. The silica-containing inner porous refractories greatly increase in porosity after casting, and this tendency is especially noticeable at its bottom. The largest porosity increase at the bottom of the silica-containing

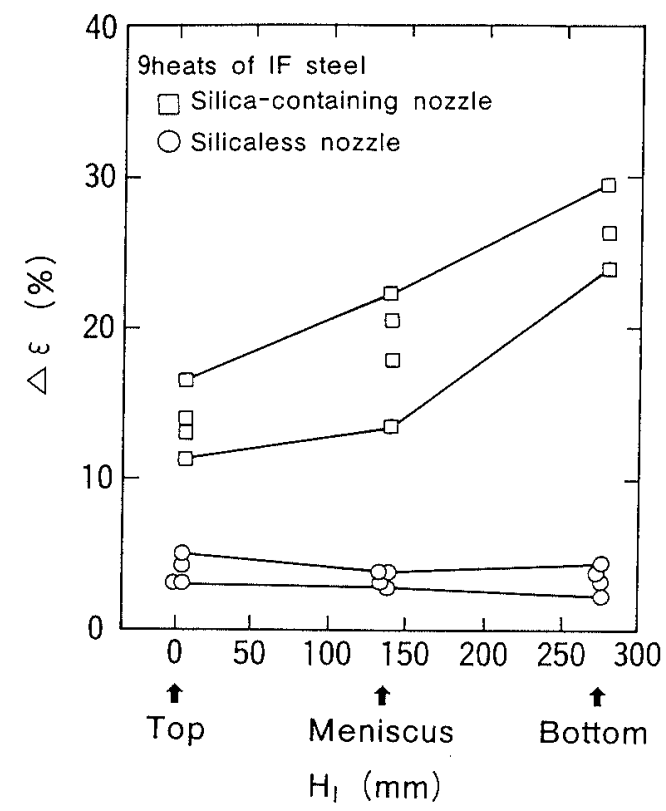

Fig. 8. Relationship between porosity increase $\Delta \varepsilon$ and distance from top of inner porous refractories $H_{1}$. 
inner porous refractories is the same as the theoretical value of $29.8 \%{ }^{3}$ ) reached when all of the silica in the inner porous refractories reacts with the molten steel. This reason may be explained as follows. Since its top and bottom are located above and below the meniscus, respectively, the inner porous refractories has a temperature distribution in the height direction. The rate of the inner porous refractories-molten steel reaction is presumably accelerated at the hottest spot or the bottom of the inner porous refractories.

The relationship between the diameter of argon gas bubbles in water, $D_{\mathrm{w}}$, and the distance from the top of the inner porous refractories, $H_{1}$, is shown in Fig. 9. The argon gas bubble diameter is large in the bottom of the inner porous refractories where the rate of the inner porous refractories-molten steel reaction is high. The argon gas bubble diameter changes in accordance with the rate of the inner porous refractories-molten steel reaction, which is changed in accordance with distance from the top of the inner porous refractories.

\subsection{Effect of Argon Gas Bubble Diameter on Incidence of Blisters}

When sheet products were inspected for blisters, it was found that all the blisters were $0.5 \mathrm{~mm}$ or more in width. On the occasion of hot and cold rolling the elongation in width direction is usually negligible small. If the width of the blisters is assumed to correspond to the diameter of argon gas bubbles entrapped in slabs, the argon gas bubbles responsible for the formation of the blisters should be all $0.5 \mathrm{~mm}$ or more in diameter.

Figure 10 shows the relationship between the number $N_{\mathrm{BU}}$ of argon gas bubbles entrapped in an IF steel slab and the index $N_{\mathrm{BH}}$ for the number of blisters caused in the sheet product rolled from the IF steel slab. The number of blisters is not clearly correlated with the number of $0.2 \mathrm{~mm}$ and larger bubbles and is weakly

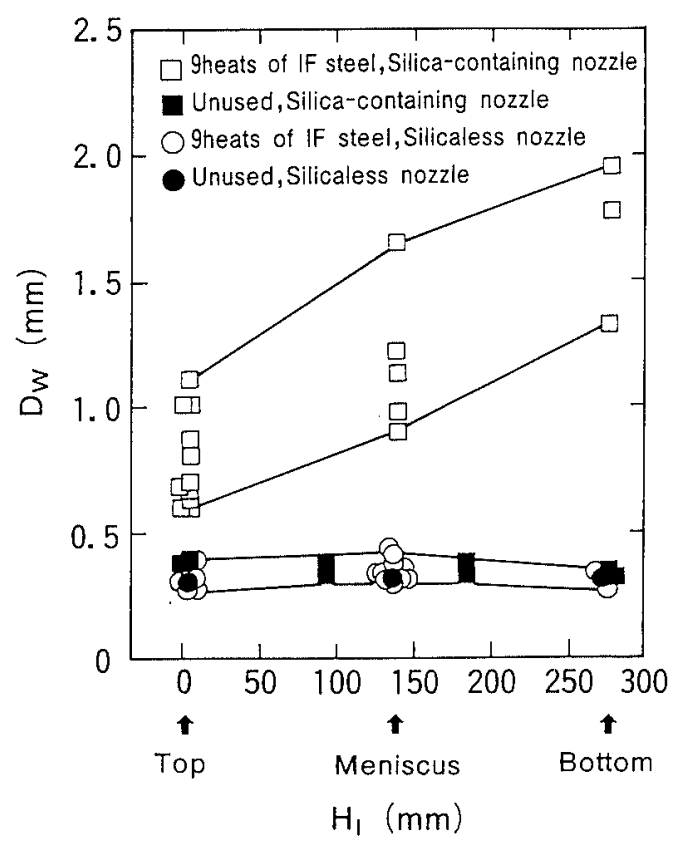

Fig. 9. Relationship between diameter of argon gas bubbles in water $D_{\mathrm{w}}$ and distance from top of inner porous refractories $H_{1}$. correlated with the number of $0.5 \mathrm{~mm}$ and larger bubbles. The number of blisters clearly increases with an increase in the number of $1.0 \mathrm{~mm}$ and larger bubbles.

From the above results, it may be considered that bubbles less than $0.5 \mathrm{~mm}$ are completely welded shut by rolling and do not turn into blisters in the rolled sheet product. In contrast, $0.5 \mathrm{~mm}$ and larger bubbles are likely to become blisters. Especially, $1.0 \mathrm{~mm}$ and larger bubbles clearly correlated with the number of blisters are presumed to have a strong impact on the incidence of blisters.

\subsection{Cause for Sequence Cast Heat Number Dependence of Blister Occurrence}

\subsubsection{Method for Estimating Bubble Diameter in} Molten Steel

To understand the mechanism of the sequence cast heat number dependence of blister occurrence, a study was made of the method of estimating the diameter of argon gas bubbles in molten steel from the argon gas bubble diameter obtained in water model experiment.

The diameter $D(\mathrm{~cm})$ of gas bubbles formed in a liquid from a single nozzle is given by the following equation. ${ }^{5)}$

$$
D=\left[\left(\frac{6 \sigma \cdot d}{\rho \cdot g}\right)^{2}+\left\{0.54\left(V \cdot d^{0.5}\right)^{0.289}\right\}^{6}\right]^{1 / 6}
$$

where $\sigma$ represents surface tension of the liquid (dyn .
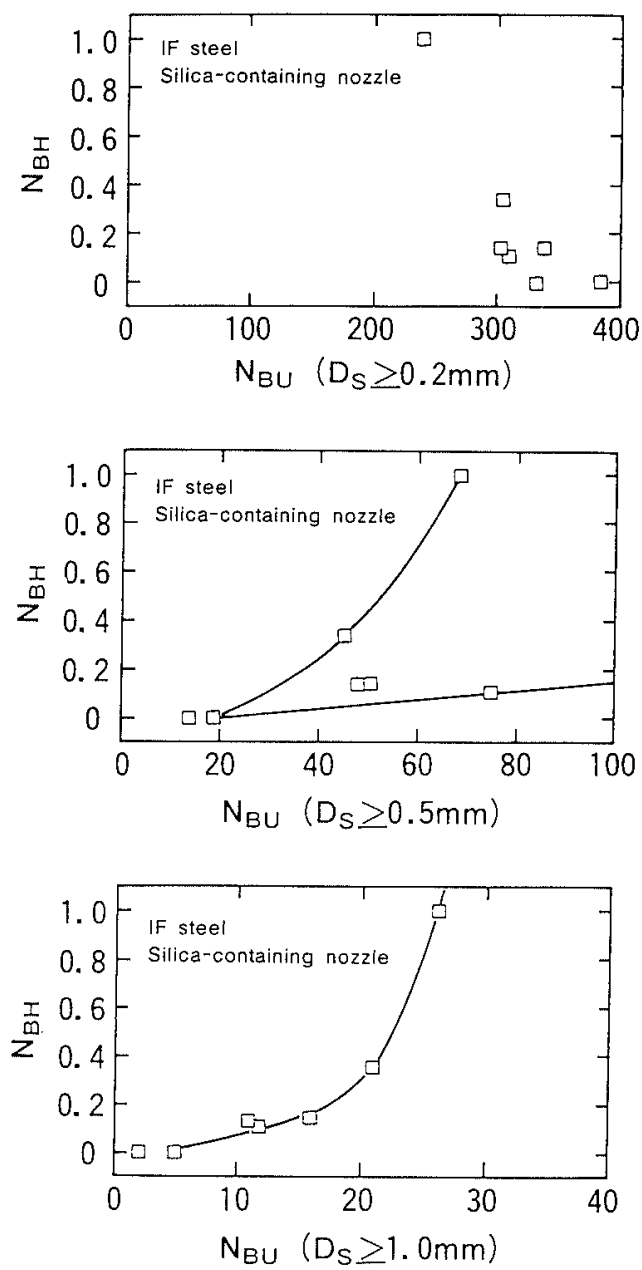

Fig. 10. Relationships between index for number of blisters in sheet $N_{\mathrm{BH}}$ and number of argon gas bubbles in slab $N_{\text {BU. }}$. 
$\left.\mathrm{cm}^{-1}\right) ; d$, outside diameter of the nozzle $(\mathrm{cm}) ; \rho$, density of the liquid $\left(\mathrm{g} \cdot \mathrm{cm}^{-3}\right) ; \mathrm{g}$, gravitational acceleration $\left(\mathrm{cm} \cdot \mathrm{s}^{-2}\right)$; and $V$, flow rate of the gas $\left(\mathrm{cm}^{3} \cdot \mathrm{s}^{-1}\right)$.

To apply Eq. (1) to the inner porous refractories of the immersion nozzle, $d$ and $V$ are taken as the pore diameter of the inner porous refractories and the gas flow rate per pore, respectively. Regarding the pores in the inner porous refractories as a collection of tubes, the number $N$ of pores per unit surface area (count $\cdot \mathrm{cm}^{-2}$ ) is given by Eq. (2), and the gas flow rate per pore is given by $\mathrm{Eq}$. (3).

$$
\begin{aligned}
& N=4 \varepsilon /\left(\pi \cdot d^{2}\right) \\
& V=Q / N
\end{aligned}
$$

where $\varepsilon$ represents porosity of the inner porous refractories (-); and $Q$, gas flow rate per unit area of the inner porous refractories $\left(\mathrm{cm}^{3} \cdot \mathrm{cm}^{-2} \cdot \mathrm{s}^{-1}\right)$. The pore diameter and porosity of unused inner porous refractories are $1.1 \mu \mathrm{m}$ and 0.20 , respectively. When the water density $\rho_{\mathrm{w}}$ of $1.0 \mathrm{~g} \cdot \mathrm{cm}^{-3}$, water surface tension $\sigma_{\mathrm{w}}$ of $72.5 \mathrm{dyn} \cdot \mathrm{cm}^{-1}$, molten steel density $\rho_{\mathrm{s}}$ of $7.0 \mathrm{~g} \cdot \mathrm{cm}^{-3}$ and molten steel surface tension $\sigma_{\mathrm{s}}$ of $1500 \mathrm{dyn} \cdot \mathrm{cm}^{-1}$ are used and when the values of $Q$ in the water model experiment and the casting experiment are substituted into Eqs. (1) to (3), the gas flow rate $V$ per pore becomes very small, and the bubble diameter can be estimated by the following equation that does not depend on the gas flow rate.

$$
D=\left(\frac{6 \sigma \cdot d}{\rho \cdot g}\right)^{1 / 3}
$$

When the conditions of the water model experiment are applied to Eq. (4), the diameter of the argon gas bubbles injected from the unused inner porous refractories is $0.37 \mathrm{~mm}$, which is in accord with the average diameter of argon gas bubbles injected from the unused inner porous refractories (reacted zone thickness: $0 \mathrm{~mm}$ ) shown in Fig. 7. This means that the diameter of the argon gas bubbles injected from the inner porous refractories can be quantitatively estimated by Eq. (4) in the gas flow region of this experiment. When the physical properties of water and molten steeel are substituted into Eq. (4), Eq. (5) is derived to describe the relationship between the in-water bubble diameter $D_{\mathrm{w}}$ and in-molten steel bubble diameter $D_{\mathrm{s}}$. The behavior of bubbles in the molten steel is discussed below by using Eq. (5) while disregarding the coalescence of bubbles in the molten steel.

$$
D_{\mathrm{s}}=\left(\frac{\sigma_{\mathrm{s}} \cdot \rho_{\mathrm{w}}}{\sigma_{\mathrm{w}} \cdot \rho_{\mathrm{s}}}\right)^{1 / 3} \cdot D_{\mathrm{w}}
$$

4.5.2. Change in Diameter of Bubbles in Molten Steel with Time

Figure 11 shows the change with time in the diameter of bubbles in molten steel as estimated from the diameter of bubbles in water by Eq. (5). The diameter of argon gas bubbles injected into the molten steel from the silica-containing inner porous refractories is about $0.5 \mathrm{~mm}$ in the initial stage of casting and then increases with an increase in casting time. Particularly, the diameter of argon gas bubbles injected from the lower part of the inner porous refractories reaches in $200 \mathrm{~min}$ the value of $1.0 \mathrm{~mm}$, which value strongly affects the incidence of blisters in the sheet product.

Figure 12 shows the relationship between the number of $1.0 \mathrm{~mm}$ and larger bubbles entrapped in IF steel slabs and the number of sequence cast heats. When the IF steel is cast using the immersion nozzle with the silicacontaining inner porous refractories, the number of $1.0 \mathrm{~mm}$ and larger bubbles entrapped in the IF steel slabs sharply increases after heat $6(225 \mathrm{~min})$. This result is in agreement with Fig. 11.

Up to heat 6 in the sequence cast, the argon gas bubbles are relatively small in diameter to make it difficult for blisters to occur in the sheet product. After heat 6 , the argon gas bubbles exceed $1.0 \mathrm{~mm}$ in diameter, and the inner porous refractories region where $1.0 \mathrm{~mm}$ and larger argon gas bubbles are formed gradually expands in scope. The incidence of blisters thus steeply increases. The change in the number of blisters as shown in Fig. 2 is probably obtained as a result of this increase. The

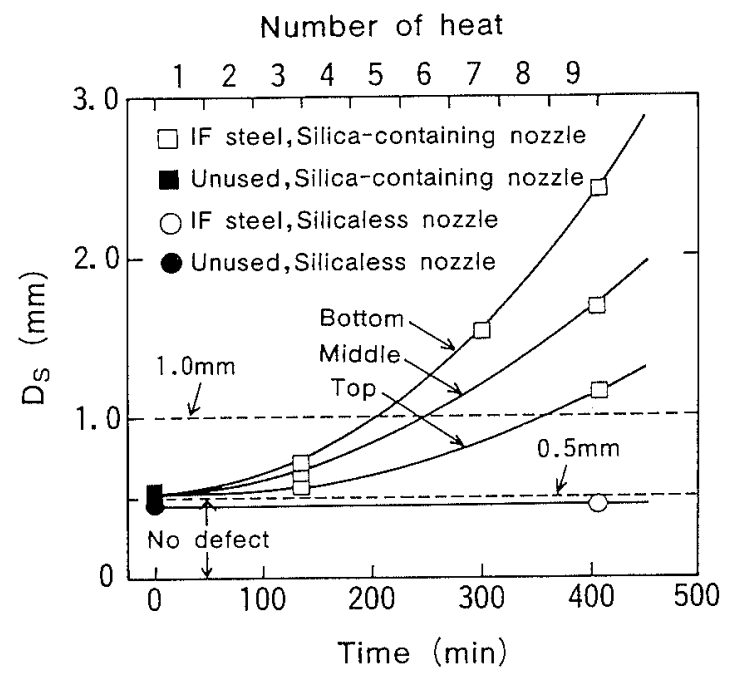

Fig. 11. Change with time in diameter of argon gas bubbles in molten steel $D_{\mathrm{s}}$ as estimated from diameter of argon gas bubbles in water $D_{\mathrm{w}}$

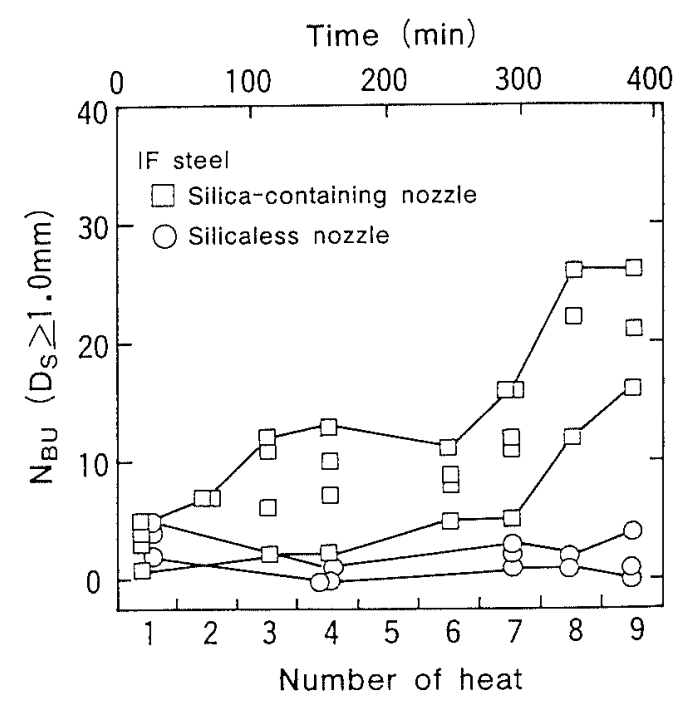

Fig. 12. Relationship between number of $1.0 \mathrm{~mm}$ and larger argon gas bubbles in slab $N_{\mathrm{BU}}$ and number of heats in sequence cast. 
mechanism whereby the incidence of blisters depends on the number of heats in the sequence cast can be explained by the increase in the diameter of argon gas bubbles due to the reaction between the inner porous refractories of the immersion nozzle and the molten steel.

\subsection{Mechanism for Prevention of Blisters by Use of Immersion Nozzle with Silicaless Inner Porous Refractories}

As evident from Fig. 11, the argon gas bubbles injected from the immersion nozzle with the silicaless inner porous refractories do not increase in diameter with an increase in the number of heats in the sequence cast. The diameter of the argon gas bubbles in the molten steel remains constant at about $0.5 \mathrm{~mm}$ from the first heat of the sequence cast. The incidence of blisters in the sheet product is thus low. When the IF steel is cast using the immersion nozzle with the silicaless inner porous refractories, the number of $1.0 \mathrm{~mm}$ and larger argon gas bubbles entrapped in the IF steel slabs is small and does not increase with an increase in the number of heats in the sequence cast, as shown in Fig. 12.

When the IF steel is cast using the immersion nozzle with the silicaless inner porous refractories, fine argon gas bubbles can be stably and uniformly injected into the molten steel. Blisters resulting from the reaction between the inner porous refractories and the molten steel are thus considered to be prevented by using the immersion nozzle with silicaless inner porous refractories.

\section{Conclusions}

The effect of the inner porous refractories-molten steel reaction on the incidence of blisters and the mechanism whereby the incidence of blisters is prevented by using an immersion nozzle with a silicaless inner porous refractories that does not react with the molten steel were studied. The following conclusions were obtained:

(1) Blisters are caused by $0.5 \mathrm{~mm}$ and larger argon gas bubbles, and particularly $1.0 \mathrm{~mm}$ and larger argon gas bubbles have a strong bearing on the incidence of blisters in the sheet product.

(2) The mechanism whereby the incidence of blisters depends on the number of sequence cast heats can be explained by the increase in argon gas bubble diameter caused by the inner porous refractories-molten steel reaction in the later heats in the sequence cast.

(3) Fine argon gas bubbles can be stably injected into the molten steel by using an immersion nozzle with a silicaless inner porous refractories that does not react with the molten steel. This stable injection of fine argon gas bubbles helps prevent the occurrence of blisters in the sheet product.

\section{REFERENCES}

1) M. Sato, M. Yoshida, H. Take, H. Yamazaki and N. Bessho: CAMP-ISIJ, 5 (1992), 1252.

2) K. Sasai and Y. Mizukami: ISIJ Int., 34 (1994), 802.

3) K. Sasai and Y. Mizukami: ISIJ Int., 35 (1995), 26.

4) K. Sasai and Y. Mizukami: Tetsu-to-Hagané, 81 (1995), 535.

5) M. Sano, K. Mori and T. Sato: Tetsu-to-Hagané, 63 (1977), 2308.

(Originally published in Tetsu-to-Hagané, 81 (1995), 965, in Japanese) 